\title{
CUMHURIYETIN İLK YILLARINDA KADIN KIYAFETİ MESELESİ
}

\author{
Yrd. Doç. Dr. Sadık SARISAMAN*
}

\section{GİRIş}

İslâm öncesi Türk kadını tesettürlü bir giyiniş içerisinde olmamıştır. Saçı açık ve örgülüdür. $O$, erkeği ile beraber at biner, ok ve yay kullanırdi ${ }^{1}$. Türkler İslầm dinine girdikten sonra karşılarında üstün bir İslâm medeniyeti ve bu medeniyetin unsurlarını hazır olarak buldular. Hazır olarak bulunan ve benimsenen unsurlardan bir tanesi de konumuzu teşekkül eden tesettür idi.

Ahzâb suresinin 59. ayetinde "Ey peygamber eşlerine, kızlarına ve müminlerin kadınlarına, dışarı çıkarken üstlerine örtü almalarını söyler, bu onların hür ve namuslu bilinmelerini ve bundan dolayı incitilmemelerini daha iyi sağlar. Allah bağışlar ve merhamet eder" denilmektedir². Örtünmede çarşaf ve peçe kullanılmasının İslâm kültürüne İranlılar'dan sirayet etmiş bir husus olduğu Prof. Dr. Afet İnan hanımefendi tarafindan ifade edilmektedir**. Müslümanlığın ilk devirlerinde sosyal sınıf farkını belirtmek üzere yalnız asil kadınlar tarafından uzun elbise giyiliyor ve cilbab denilen yüz örtüsü takılıyordu. Hazreti Ömer sosyal dengeyi bozucu sınıf farklarının bariz bir şekilde ortaya çıkmaması için bu giysiyi yasaklamışırı. Fakat Abbasiler'den itibaren tarikatlar ve medreselerin kuvvetli etkisi altında bulunan şehirlerde kadınların kapalı gezmesi dinin gereği olarak görülmeye başlanılmıştır ${ }^{3}$.

* $\quad$ KTƯ Giresun Fen-Edebiyat Fakültesi, Ögretim Ùyesi.

1. Ibrahim Kafesoğlu, Türk Milli Kültürü, (17. Bask1), Istanbul-1998, s. 229; Afet Inan, Atatürk ve Türk Kadın Haklarının Kazanılması, Tarih Boyunca Türk Kadın Hakları ve Görevleri, (4. Baskı), Istanbul-1982, s. 26, 29, 34.

2. Diyanet Işleri Başkanlığı, Kuran-1 Kerim ve Türkçe Anlamı, (Meâli), (15. Baskı), Ankara-1988, s. 425.

** Çarşaf kelimesi Farsça çarșebden bozmadır. Çarşebin aslı da gece uykusu anlamına gelen çaderşebdir (Mehmet Zeki Pakalın, Osmanlı Tarih Deyimleri ve Terimleri Sözlüğü I, lstanbul-1993, s. 327).

3. Afet lnan, a.g.e., s. 33 . 
Tesettürü oluşturan çarşaf, peçe*** ferace gibi giysiler İslâmiyete girişten sonra Türk kadınları tarafından da yüzyıllarca giyildi. Hatta Türklerle birlikte yaşayan Rum ve Ermeniler dahi bu kıyafetleri benimsemeye başladılar. Örneklemek gerekirse, 1847 Ağustosu'nda Tirebolu'yu ziyaret eden Fransız gezgini Xavier Hommaire de Hell'in seyahatnamesi zikredilebilir. Hell, Tirebolu'daki Rum ve Ermeni kadınlarının da Türk kadınlan gibi vücutlarını saran mavi kare desenli büyük çarşaflar örtündüklerini kaydetmektedir ${ }^{4}$. Hell'in kaydettiği örtünün çarşaf değil başka bir giysi olması muhtemeldir. Zira, Mehmet Zeki Pakalın, çarşafın tanzimatdan sonra hacılar vasıtasıyla Arabistan'dan Osmanlı toplum hayatına intikal eden bir giysi olduğunu belirtir. Onu esas alan Sebahattin Türkoğlu'da aynı ifadeleri tekrarlar. Ancak, bu iki araştırmacı çarşafın yaygınlaşmasını sağlayan gelişmeler hakkında biraz farklı ifadeler kullanırlar. Türkoğlu yaşmak ve ince feraceyi yasaklayan emirnamenin tarihini 1870 olarak verirken, Pakalın 1889 olarak gösterir. Pakalın'a göre 1889 Ramazan'ın da paşa rütbesindeki bir kişinin yakınlan bayanlara vuku bulan bir tasallut nedeniyle Sultan II. Abdulhamit yaşmak ve feraceyi yasaklamıştır. Bundan dolayı İstanbul'da çarşaf yaygınlaşmıştır .

Öte yandan Tanzimat sonrasında Osmanlı toplumunda ve Devlet düzeninde meydana gelen batıya açılma politikaları bir süre sonra tesettürün de sorgulanması sonucunu meydana getirmiştir. Abdullah Cevdet, 1908 Meşrutiyet inkılâbından sonra Ictihad'da peçe ve çarşaf meselelerini tartışmaya açtı. Bu tartışmalara erkekler dışında bayan yazarlar da katıldı. Tesettür meselesi bilhassa İctihad ve Sebilüreşad dergileri arasında uzun tartışmalara yol açtı. İctihad yazarları tesettür meselesini sadece bir örtünme sorunu olarak değil, kadının sosyal, kültürel ve iktisadi hayatta yer almasını engelleyen bir problem olarak da değerlendirdiler. Tesettürden kurtulmanın kadının kurtuluşu anlamına geleceğini ifade ettiler.

*** Ismail Hakkı Danişmend'in belirttiğine göre Osmanlı'da peçe ilk defa Sultan I. Murat devrinde Bursada ortaya çıkmıstır. Karamanoğlu Aladdin'in Hamitoğlu Ilyas Bey' in memleketinde katliama başlaması üzerine buradan üç aşiret Osmanlı topraklarına firar ettiler. Sultan Murat bunları temiz ve uslu adam olduklan için Bursa'ya yerlestirdi. Ancak bu aşiretlerin kadınlan cok güzel olduğu için Bursa'nın erkekleri bunları seyretmeye başlayınca ulemalar tarafından bu kadınlann yüzlerinin örtülmesine karar verildi. Sonralan bu kıyafet diğer kadınların da hoşuna gittiğinden herkes peçe örtmeye başladı (1smail Hakkı Danişmend, Türk Irkı Niçin Müslüman Oldu, Konya-1978, s. 85, 86).

4. Mustafa Aydın, "XIX. Yüzyılın Ilk Yarısında Bazı Seyyahların Tirebolu Izlenimleri", Giresun Kültür Sempozyumu, Istanbul-1998, s. 37.

5. Mehmet Zeki Pakalın, a.g.e., s. 327, 329; Sebahattin Türkoğlu, "Çarşaf", Türkiye Diyanet Vakfi Islâm Ansiklopedisi VIII, İstanbul-1993, s. 231. Çarşaf ile ilgili bir başka gelişme Sultan II. Abdülhamit'in 1892 'de bu giysiyi yasaklaması olmuştur. II. Abdülhamit çarşaf altuna gizlenen bazı erkeklerin çeşitli suçlar işlemeleri ve saraya girmeye tesebbüs etmeleri üzerine 2 Nisan 1892 tarihli bir emirnâme ile çarșafı yasakladı. Ancak bu yasak sadece saraya girenler için tatbik edildi. Bunun dışındaki insanları kapsamadı (Sebahattin Türkoğlu, a.g.m., s. 231). 
Kılıçzade Hakkı Bey, tesettürün kalkmasının sağlayacağı yararlan şu şekilde sistemleştirmiştir:

1- Kızlarımız ve kadınlanımız serbestçe öğretim yapabileceklerdir.

2- Genel hayata katılabilecek, vatan hizmetinde bulunabileceklerdir. lacaktır.

3- Herkes gördüğü kişi ile evlenecek, aile kuracak, boşanmalar aza-

4- Görgü artacak, çocuklar iyi geçinecektir.

5- Kadın, savaşa giden kocasının, biraderinin dükkanını, mağazasını çalıştırabilecektir.

6- Kadınlar meclislere devam edeceklerinden erkekler terbiyeli ve fedakar hale gelecektir.

7- Kadınlar, haklarını aramaya başladıkça hastalıklar azalacaktır.

Diğer taraftan Zekâ, Sehbal gibi dergiler de batılı kadının resimli giysi modellerini yayınlayarak, Türk kadınını giyim, kuşam, cilt bakımı ve davranış biçimi olarak tam bir batılı kadın gibi eğitmeye çalışmışlardir.

Karşı tarafın görüşlerine gelince, Sebilüreşad yazarları İctihad'ın fikirlerinin 350 milyonluk bir İslâm devletinde (?) savunulmasını hayretle karşıladıklarını ifade ederler. Onlar İctihad'ın basın hürriyetini ağzına geleni söylemek olarak algıladığını ve bunu kötü yönde kullandığını iddia ederler. Kılıçzade Hakkı'nın sistemlestirdiği maddeleri tek tek cevaplandırarak tesettürün kadının hiçbir hakkına engel olmadığı gibi tesettürlü olarak tahsil edilip çalışabileceğini belirtirler.

İslâmcılardan tesettüre uymak için başı örtmenin, vücut çizgileri belli olmayacak şekilde kıyafet giymenin yeterli olduğu görüşünü savunanlar da olmuştur. Bu görüşü savunanlar yaşmak, terace, çarşaf, peçe gibi giysilerin dine sonradan giren adetler olduğunu kabul ederler.

İslâmcılara göre kadının açılmasını isteyenler hürriyet adına, kadınların örtülerini çıkanı balolara, tiyatrolara gitmelerini, erkeklerin şehvetli bakışlarına maruz kalmalarını, kocalarından başkalanyla raks etmelerini, istedikleri yerlere serbestçe gidebilmelerine arzu etmektedirler. Oysa, tesettür kadının namusunun iffetinin simgesidir. Ayşe Mediha, "Müslüman Kadını Hürdür, Mesuttur", başlıklı bir yazısında "Bizim gayri mesut olduğumuzu iddia edenler, bizim lane-i ismetimize (masum yuvamiza) kadar duhul edebilmişler midir?", diye sormaktadır. Yine İslâmcılar tesettürü kaldırma gayretlerini Müslüman mahallesinde salyangoz satmak şeklinde yorumlamışlardır ${ }^{6}$. Ünlü Şair Mehmet Akif (Ersoy) da bu tartışma-

6. Şefika Kurnaz, “II. Meşrutiyet Döneminde Türk Kadını”, Istanbul-1996, s. 48-57. 
larda İslâmcı kesimin keskin kalemleri içerisinde yer aimıştır. O, Safahatı'ndaki bir şiirinde şu mısralarla sert bir şekilde fikir ve duygularını ifade etmektedir.

\section{Kızımin iffeti batmakta rezilin gözüne \\ Acırım tükrüğe billahi tükürsem yüzüne}

Osmanlı Devleti'nin tesettür konusundaki politikalanı da İslâmcılarla uyuşmakta idi. 1909 yılında hükümet kadınların tesettüre uygun şekilde sokağa çıkmaları konusunda karar almışıır. Bu karara uymayanların içişleri bakanlığı tarafından takibata uğrayacaklanı uyarısında bulunulmuştur ${ }^{8} .1911$ yılında da şeyhülislâmlık makamından kadınların Avrupalı hanımlar gibi giyinmemeleri konusunda bir ihtar geldi. Yine Mehtap Mecmuası'nda Müslüman kadınların örtünmesi aleyhinde yazı yazan Kafkasyalı Mehmet Hadi Efendi ülke dışına çıkarıldı?

İttihat ve Terakki'nin lideri olan Enver Paşa'da kadın kıyafetinde tesettürden yana olmuștu. Nitekim, 1916 Ekimi'nde kuruluş hazırlıklanna başlanılan Birinci Ordu Kadın İş̧i Taburu için düzenlenen talimâtnamede kadın işçilerin, kıyafet olarak şalvar, ceket ve başörtüsü taşımalan kararlaştınlmışken Enver Paşa bunu yeterli görmemiş, yeldirme tarzında uzunca bir elbise giymelerini de şart koşmuştur ${ }^{10}$.

\section{YORDU}

1. ATATÜRK KADIN KIYAFETI MESELESINE NASIL BAKI-

Atatürk'ün kadın kıyafeti meselesine nasıl baktığını anlayabilmek için bu konudaki konuşmalarını kronolojik bir sıra ile aktarmak lazımdır. O, Ocak 1923'de yaptığı bir konuşmada din gereği olan tesettürün kadınlara sıkıntı çektirmeyecek ve adaba muhalif olmayacak şekilde basit olmasını tavsiye etmiştir ${ }^{11}$. Yine aynı yılın Mart ayında yaptığı bir konuşmada da tesettürün kadınlara zorluk vermeyecek, iktisadi ve sosyal hayatta erkeklerle birlikte bulunmalarını engel olmayacak basitlikte olmasını önermiştir ${ }^{12}$. O, kadın kıyafetinde yenilik yapmayı düşünmediklerini de kaydetmiş, milletin temayül göstereceği kıyafetlerin yaygınlaşmasının doğru olacağını ifade etmiştir ${ }^{13}$. Görüldü̈̆ü üzere kıyafette yenilik için teşvik edici bir tutum söz konusudur.

7. Mehmet Akif Ersoy, Safahat, Istanbul-1996, s. 196.

8. Sefika Kurnaz, a.g.e., s. 55, 57, 121.

9. Sefika Kurnaz, a.g.e., s. 121.

10. Sadık Sansaman, "Birinci Ordu Birinci Kadın Ișçi Taburu”, Atatürk Araștırma Merkezi Dergisi, XIII/39, Kasım 1997, s. 700.

11. Enver Ziya Karal, Atatürk'den Düşünceler, Istanbul-1986, s. 57.

12. Enver Ziya Karal, a.g.e., s. 57.

13. Enver Ziya Karal, a.g.e., s. 58. 
Atatürk Ağustos 1925'de şapka inkılâbı için gittiği Kastamonu'da yaptığı konuşmada kadın kıyafeti hakkındaki düşüncelerine biraz daha açıklık getirmiştir. $\mathrm{O}$, Türk kadınına yüzünü gözünü kapatan kıyafetleri yakıştıramadığını ifade etmektedir. Yine yakınından geçen erkeklere sırtı$\mathrm{n}$ dönen veya yere oturarak yumulan kadınların bu tavırlarını medeniyetle bağdaşmayan gülünç tavırlar olarak değerlendirmektedir ${ }^{14}$. $\mathrm{O}$, Türk kadınının yüzünü dünyaya göstermesinde ve gözleri ile dünyayı incelemesinde korkulacak bir durum olmadığını da kaydetmektedir ${ }^{15}$.

Atatürk bir başka konuşmasında ise teşvik edici tavrını daha da netleştirmiş "kadın meselesinde cesur olalım. Kuruntuyu bırakalım... açılsınlar, onların zihinlerini ciddi ilimler ve fen ile süsleyelim. Namusu, bilimsel ve sağlıklı bir şekilde açıklayalım. Şeref ve gurur sahibi olmalarına birinci derecede önem verelim"16 ifadelerini kullanmıștır. Görüldüğü üzere bu zamana kadar açıkça tesettüre karşı çıkmayan Mustafa Kemal Paşa bu defa kadınların açılmasını şiddetle önermektedir.

Atatürk'ün sohbetlerinde genellikle kadınlar da yer almıștır. O, böylece kadını sosyal hayata dahil etmek için öncülük görevi yapmış olmaktadır. Eşi Latife Hanım da zamanının en modern kadını görüntüsüyle Gazi'nin yanında yer almış ve ona destek olmuştur.

\section{BASINDA MODERN KADIN KIYAFETI LEHINDE KAMU- OYU OLUŞTURMA GAYRETLERI}

Bazı basın organlan Seyh Sait isyanının bastırılmasından sonra şapka inkılâbı, tekke ve zaviyelerin kapatılması, medeni kanunun kabulü gibi peşpeşe yapılan inkılâplarla muhalif zihniyetin tamamen sindirildiği bir zamanda kadın kıyafeti meselesini özellikle gündeme getirmeye çalıştılar. Hükümeti kadın kıyafeti konusunda da bir kanun çıkarmaya teşvik ettiler $^{17}$. Kadın kıyafetinde zorlama yapılmasının şart olduğunu hatta bu konuda geç bile kalındığını ifade ettiler ${ }^{18}$.

Erkek kıyafetinde nasıl fes rejim için tehlike teşkil eden bir zihniyetin sembolü olarak değerlendirilerek karşı çıkılmışsa, kadın kıyafetinde de çarşaf ve peçenin hedef alınması gerektiğine işaret ettiler. Çarşafı sadece kadının yüzünü örten bir örtü değil, sosyal, kültürel ve iktisadi ha-

14. Atatürk'ün Söylev ve Demeçleri II, (4. Baskı), Ankara-1989, s. 227.

15. Atatürk'ün Söylev ve Demeçeri II, s. 221.

16. Genel Kurmay Başkanlı̆̆ı, Atatürkçülük (3. Kitap) Atatürkçü Düşünce Sistemi, Istanbul-1984, s. 161; Afet Inan, M.K. Atatürk'ün Karlsbad Hatıralar, Ankara-1983, s. 45 .

17. Yeşil Giresun, Numro: 39, 6 Kanunisani/Ocak 1927; Numro: 40, 13 Kanunisani/ Ocak 1927; Numro: 41, 20 Kanunisani/Ocak 1927; Numro: 130, 13 Eylül 1928.

18. Yeșil Giresun, Numro: 130; Yeşil Giresun, Numro: 131, 20 Eylül 1928; Numro: 141, 29 Teşrinisani/Kasım 1928. 
yatta yer almasını ve haklarına sahip çıkmasını engelleyen bir tecrit aracı olarak da gördüler ${ }^{19}$.

Yine peçe ve çarşaf geri kalmışlığın sembolü olarak değerlendirilmiş ${ }^{20}$, kadınlanın fikren olduğu gibi şeklen de medeni olmalan gerektiği üzerinde durulmustur. Kapanmanın asri kıyafeti reddetmek olduğu kaydedilerek, saklanmak ve erkekten kaçmak usullerini kaldırmakta bir an bile tereddüt gösterilmemesi önerisinde bulunulmuştur ${ }^{21}$.

Öte yandan çarşaf ve peçenin İslâmın bir gereği olmadığı anlatılmış, namus ve iffetin peçede, çarşafta değil kadının öz benliğinde bulunduğu kaydedilmiştir. ERkekler nasıl ki başlanına şapka takmakla Hıristiyan olmadılarsa, kadınlanı da peçe ve çarşafı bırakmakla dinden çıkmayacaklarn ifade edilmiștir. Üstelik bu giysilerin İslâmi olmayıp Türklere Rumlar, Ermeniler ve Îranlılardan intikal ettiği üzerinde durulmuş, Hazreti $\mathrm{Mu}$ hammed zamanında kadınlanın yüzlerinin açık olduğu iddiasında bulunulmuştur ${ }^{22}$.

6 Aralık 1928 tarihli Emel imzalı bir yazıda kadın giyiminde gerçek İslâmi tesettürün şapkalı, mantolu, kostümlü kıyafetlerle temin edilebileceği belirtilerek şu görüșe yer verilmiștir:

19. Bu görüş, Şükrü Turgut tarafından kaleme alınan Peçe ve Çarşaf adlı bir şïrde de ifade edilmiştir. Bu şiiri aynen aktarmayı uygun görüyoruz.

\section{PEÇE VE ÇARŞAF}

Birkaç senedir bu karanliklar Teceddüde karș bir duvar oldu. Bu siyah zindanda pembe yanaklar Güneşe gülmeden sarard l soldu

Tam on asirdir ki bu siyah perde Kadının hakkını bir sıfır yaptı Küçük düşüyorken hemen her yerde Inat edip yine beze tapts.

Evde ya bir vazo ya bir gül gibi

Okşanır, koklanır, kırılır, solar

Veyahut sen sakrak bir bülbül gibi

Ruhundan pek perran nağmeler çağlar.

$$
\text { 6.5.1929 Sükrü TURGUT }
$$

20. Yeşil Giresun, Numro: 40, 13 Kanunisani/Ocak 1927.

21. Yeșil Giresun, Numro: 131, 20 Eylül 1928. Bu konuda basında yer alan bazı mesajlari burada aktarmak istiyoruz.

"Necip, asil kadınlarımız ne düşünüyorlar ve neyi bekliyorlar, peçenin o zalim örtünün karanlıkları altında terleyen, sendeleyen Türk kadınlan peçeyi kaldırıp atmanın artık zamanı gelmiștir ve geçmiștir.

"Açık ve pak alnınızı şüpheli, lekeli insanlar gibi saklamayınız. Bu siyah perdenin, o genis torbanın içinden çıkarak dünyaya hayata bakınız" (Yeşil Giresun, Numro: 142, 6 Kanunievvel/Aralık 1928).

22. Yeșil Giresun, Numro: 40, 13 Kanunisani/Ocak 1927. 
"Köylülerin peştemallerle yaptıklan tesettür ve şehirlilerin kara kefenlerle yaptıkları tadilatı (değişiklikleri) görmüyor musunuz? Kadınlanı mahrem ve şehvetengiz yerleri, namahrem yerleri de el ve yüzü olduğuna nazaran, köylü kadının bacaklarını açarak gezmesi, bel ve gögüs kıvnm ve inhinâlarını (kavislerini) hissettirecek derecede peştemallerini bağlayışı kara kefenlerle gezenlerin bir çoklarının da eteklerinin çok kısa oluşu gibi tamamen açık olan şekiller tesettür addediliyorsa da güzel bir kostüm ve manto ile vücudunu örten ve saçlarını derleyip, toplayıp şapka giyen ve bu suretle tesettüre tamamen riayet eden kadınların kiyafetleri neden acayip görülüyor.

"Kapalılık Müslümanın (İslâmın) emrettiği kapalılık kıyafeti sade bir tarzda giyinmiş olan şapkalı, mantolu, kostümlü kadının kıyafetidir. Açık kıyafet de peştemalli ve kara kefenli kadının kıyafetidir"23.

Kadınlarımızın hâlâ çarşaf giymeye devam etmelerinin onlanı dış dünyada acayip kılıklı ve medeniyetten yoksun insanlar olarak tanıttı̆̆ına dikkat çekilmiş olup, peçe ve çarşaf kullanımının pahalı olması nedeniyle iktisadi açıdan da sakıncalı olduğuna işaret edilmiştir ${ }^{24}$. Ayrıca, çarşaf bilgisizlik ve cehaletin bir ürünü olarak değerlendirilerek aydınlanan Türk kadınında bu giysinin yaşamak ve tutunmak imkanı bulamayacağı kaydedilmektedir ${ }^{25}$.

Bu arada tesettüre karșı olmakla birlikte kadın kıyafetinde orta yolu önerenler de olmuştur. Kadınların tesettür tartışmasına Şadan imzasıyla katılan bir bayan Türk kadınının Fransız ve Amerikan kadınına benzetilmemesini istemekte, çarşaflara bürünen kadınların birdenbire tuvaletlerle sokağa çıkar vaziyete getirilmemesi gerektiğine işaret etmektedir ${ }^{26}$. Yine bir başka yazıda da peçe ve çarşaftan sıyrilan kadınlanımızın ahlak bozu$\mathrm{cu}$ dans illetine yönelmemeleri tavsiye edilmektedir ${ }^{27}$. O günlerin kimi aydın çevrelerinde dahi kadınlann dans etmesinin ahlak bozucu bir davranış olarak değerlendirilmesi dikkat çekicidir.

\section{PEÇE VE ÇARŞAFI YASAKLAMAYA YÖNELIK BAZI TE- ŞEBBÜSLER}

Şapka inkılâbının akabinde yenilikçi görüşü benimseyenler kadın kıyafeti konusunda da bir inkılâp beklentisi içerisine girdiler. Hatta, bazı il ve ilçelerde peçe ve çarşaf giyilmesi yasaklandı. Ancak Ankara'nın desteği alınamadığı için bu teşebbüsler başarısızlıkla neticelenmiştir.

Tirebolu Belediyesi 7 Ekim 1926 günü aldığı bir kararla ilçede peçe takılmasını yasakladı. 48 saat içerisinde peçeyi terk etmeyen kadınların cezalandırılacaklarını ilan etti. Diğer taraftan kadınlara öncülük etmek

23. Yeşil Giresun, Numro: 142, 6 Kanunievvel/Aralık 1928.

24. Yeşil Giresun, Numro: 131, 20 Eylül 1928.

25. Yeșil Giresun, Numro: 130, 13 Eylül 1928.

26. Yeşil Giresun, Numro: 143, 13 Kanunievvel/Aralık 1928.

27. Yeşil Giresun, Numro: 40, 13 Kanunisani/Ocak 1927. 
üzere Tirebolu Kaymakamı Mehmet Emin Bey`in hanımı Tütün Tekeli memuru Hasan Bey'in kızı ve Merkez Kız İlkokulu öğretmen muavinlerinden Safiye Hamit Hanım sokak sokak dolaşarak tesettürden sıyrılma konusunda Tirebolulu bayanların cesaretini artırmaya çalıştılar. Ancak, bu çalışmalardan beklenen sonuçlar alınamadı. Tirebolulu bayanlar peçe takmaya devam ettiler ${ }^{28}$.

Trabzon Vilayet Meclis-i Umumisi de Aralık 1926'da kadınlann peçe takmalarını yasakladı. Halka 10 gün süre tanıdı. Bu sürenin bitiminde hâlâ yüzünde peçe görülecek kadınların hüviyet tespiti için karakollara sevk edileceğini ilan etti ${ }^{29}$. Ancak, belirtilen sürenin bitiminde de bayanlarnn peçe takmaya devam ettikleri görüldü. Bunlar hüviyet tespiti için karakollara sevk edildiler. Fakat hüviyet tespiti yapıldıktan sonra da peçe takmayı sürdürdüler. Diğer taraftan peçelerin kaldırıldığı il ve ilçelerde kadınlar sokağa çıkmamayı tercih ettikleri için iktisadi hayatta da sıkıntılar yaşanmaya başlamışti $1^{30}$.

Peçelerin kaldınılması meselesi Giresun'da da gündeme geldi. Ocak 1927 'de Giresun valisi Rami Bey ile bu konuda bir röportaj yapılmıştır. Rami Bey Vilayet Umumi Meclisi'nin ilk toplantısında peçelerin kaldırılacağı sözünü vermiş olmasına rağmen ${ }^{31}$ vilayet meclisinden böyle bir karar hiçbir zaman çıkmadı. Hatta gündeme dahi alınmadı. Valinin söz vermiş olmasına rağmen bu meseleyi meclis gündemine dahi getirmemiş olması Ankara'dan almış olduğu bir uyandan mı, yoksa yerel sebeplerden mi kaynaklanmış olduğu anlaşılamamıştır.

Diğer taraftan Sivas'ta 1928 yılı Kasım ayında Türk Ocağı'nda toplantı yapan aydın ve tüccarlardan 50 kişi peçe ile mücadele kampanyası başlattılar. Bunlar kendi ailelerine peçe ve çarşafı çıkarttıkları gibi bütün Sivas halkını da bu giysilerden arındırma gayeti içerisine girdiler ${ }^{32} . \mathrm{Bu}$ kampanya kısa zamanda etkisini göstermiş olup, Belediye Başkanı Hayri Bey'in daveti üzerine bütün mahallelerin ihtiyar heyetleri peçe meselesini görüssmek üzere bir toplantı yaptılar. Bu toplantıda peçe ve çarşafın kaldırılması meselesi umumiyetle kabul görmüş olup, bu konuda gayret gösterilmesi karar altına alınmıştır ${ }^{33}$.

Bundan takriben yedi yll sonra 1935 'deki Cumhuriyet Halk Partisi kurultayında çarşafın yasaklanmasına dair bir teklif verildi ise de kabul görmedi ${ }^{34}$. Hiçbir zaman bu mesele Türkiye Büyük Millet Meclisi'ne kanun teklifi olarak intikal etmiş değildir.

28. Yeșil Giresun, Numro: 30, 29 Teşrinievvel/Ekim 1926.

29. Yeşil Giresun, Numro: 36, 10 Kanunievvel/Aralık 1926.

30. Yesil Giresun, Numro: 39, 6 Kanunisani/Ocak 1926.

31. Yesil Giresun, Numro: 39, 6 Kanunisani/Ocak 1927.

32. Yeşil Giresun, Numro: 138, 8 Teşrinisani/Kasım 1928.

33. Yeşil Giresun, Numro: 141, 22 Teşrinisani/Kasım 1928

34. Bernard Lewis, Modern Türkiye'nin Doğuşu, (Çev: Metin Kıratı), (2. Baskı), Ankara-1984, s. 270. 


\section{SONUÇ}

Mustafa Kemal Paşa kadın kıyafeti konusunda teşvik edici idi, zorlayıcı değildi. Şapka intılâbında olduğu gibi kadın kıyafeti konusunda da kanun çıkarılması gerektiği yolundaki önerilere olumlu bakmadı. Kadının sokaktaki giysisine karışmadı. Ancak, devlet dairelerinde kıyafet yönetmelikleri ile modern giyimi hakim kıldı. Şapka intılâbındaki olaylar nedeniyle peçe ve çarşafın kaldırılmasına yönelik bir kanun çıkartılmasından vazgeçilmiş olabilir.

Mustafa Kemal Paşa meclislerinde çağdaş giyimli bayanlara yer verdi. Onlara iltifat etti. Onun bu tutumu modern giyimi özendirici oldu. Eşi Latife Hanım döneminin en çağdaş kadını görünümünde idi. İl ve ilçelerdeki bürokrat hanımları, bayan öğretmenler ve memurlar da aynı yolu takip ettiler ${ }^{35}$. Peçe, çarşaf ve tesettür meselesinin çözümünün kadınlann kültür seviyesinin yükselmesinde olduğu görülmüş ve bu yöne ağırlık verilmiştir ${ }^{36}$. Aynca, halka benimsetilecek olan diğer inkılâpların tesirlerinin de zamanla bu problemin çözümüne katkıda bulunacağı düşünülmüştür ${ }^{37}$.

Bazı şehir ve ilçelerde vilayet meclisleri veya belediye ve idare heyetleri çarşaf ve peçenin kaldırılmasına dair kararlar aldılar. Ancak, bu kararlarını uygulayamadılar. Bu meselede sonuç alınamamasının sebeplerinden en önemlisi bir kanun çıkanılmamış olmasıdır. Yani alınan kararların tatbikini sağlayacak hukuki zeminin oluşturulamamasıdır.

Bir başka sebep ise, çarşaf örtmeyen kadının İslâmın emrettiği tesettürün dışına çıkmıs olacağı inancı idi. Çarşaf ve peçelerini atan hanımların iffet hislerini de bununla birlikte atmış olacaklan görüşü yaygın$\mathrm{d}^{38}$.

Öte yandan kadınların çarşaf ve peçeyi giymeye devam etmelerinde gelenek ve alışkanlıkların rolünün bulunduğuna da şüphe yoktur ${ }^{39}$. Bundan dolayıdır ki Medeni Kanun'un kabulünden sonra Giresun'da yapılan ilk resmi nikahta gelinin peçesi nikah süresince güçlükle çıkartılabilmiş$\mathrm{ti}^{40}$.

35. Yeşil Giresun, Numro: 146, 3 Kanunisani/Ocak 1929.

36. Izler, Sayı: 14, 1 Haziran 1926, s. 16; Yesil Giresun, Numro: 67, 21 Temmuz 1927. Bir gazete yazısında "Aydınlanan bilgili ve kültürlü kadın her hakkını içinde boğdurduğumuz o esaret maskesi olan çarşafları dişleriyle yırtar", denilmektedir (Yeşil Giresun, Numro: 130, 13 Eylül 1928).

37. Sulhi Dönmezer, “Atatürk Inkılaplanı ve Sosyal Değişme Teorileri”, Atatürk Araştırma Merkezi Dergisi V/15, Temmuz 1989, s. 534.

38. Yesil Giresun, Numro: 149, 24 Kanunisani/Ocak 1928.

39. Yeşil Giresun, Numro: 130, 13 Eylül 1928.

40. Yeşil Giresun, Numro: 142, 6 Kanunievvel/Aralık 1928. 
Bu giysilerin kullanılmaya devam edilmesindeki bir diğer sebepte erkeklerin kıskançlıkları ve kadınlar üzerindeki baskılanı idi. Erkekleri böyle davranmaya iten psikolojik nedenler içerisinde güven eksikliği de bulunabilir ${ }^{41}$.

41. Atatürk'ün Söylev ve Demecleri II, (4. Bask1), Ankara-1989, s. 221; Yeşil Giresun, Numro: 141, 29 Teşrinisani/Kasım 1928. Bu iddiayı destekler mahiyetteki bir yazısinda su ifadelere yer verilmektedir.

"Bugünlerde nereye gitseniz, herhangi bir mahallede otursanız herkesin ağzında ișittiniz mi? Peçeler kalkıyormuş. Allah Allah bu işler Islâmiyete yakışır mı? Daha neler göreceğiz. Ben ailemi katiyyen sokağa çıkartmam. Akşama kadar evde otursun. Akraba ve komşularına gitmek ister ise geceleri gitsin, diyorlar" (Yeşil Giresun, Numro: 40, 13 Kanunisani/Ocak 1927). 